\title{
Diener electronic weiter auf Wachstumskurs - neues Gebäude für die Lohnbehandlung
}

mit Standard Pulverlack

\section{Schichtdicke $=$ ca. $90 \mu \mathrm{m}$}

\section{KABE Farben Ultradünnschichtpulver}

\author{
Schichtdicke $=$ ca. $25 \mu \mathrm{m}$
}

\section{KARL BUBENHOFER AG}

Karl Bubenhofer AG

CH-9200 Gossau, Tel. +41 (o) 713874141 pulver@kabe-farben.ch, www.kabe-farben.ch

KABE Pulverlack Deutschland $\mathrm{GmbH}$

D-76676 Graben-Neudorf, Tel. +49 (o) 725599161 info@kabe-pulverlack.de, www.kabe-pulverlack.de
D er Plasmatechnik-Spezialist Diener Electronic $\mathrm{GmbH} \& \mathrm{Co}$. KG bezieht in Ebhausen rund 100 Meter Luftlinie von der Firmenzentrale entfernt ein weiteres, 845 Quadratmeter großes Gebäude. Dort zieht die Diener Plasma GmbH ein, eine Tochter der Diener electronic, die auf Lohnbehandlung nach ISO 9001:2008 und 13485:2003 spezialisiert ist. "Steigende Auftragseingänge in der Lohnbehandlung sowie neue Plasmaanwendungen machen diesen Schritt notwendig", sagt Christof Diener, Geschäftsführer von Diener. Plasmabehandlung findet Anwendung beim Entfernen von Fetten, Ölen, Oxiden oder Silikonen (LABS-frei), bei der Bond-, Löt- oder Klebevorbehandlung sowie bei der Lackiervorbehandlung von Metallteilen. Diener Electronic GmbH \& Co. KG erzielte 2011 einem Umsatz von 8,2 Mio. Euro und beschäftigt 110 Mitarbeiter.

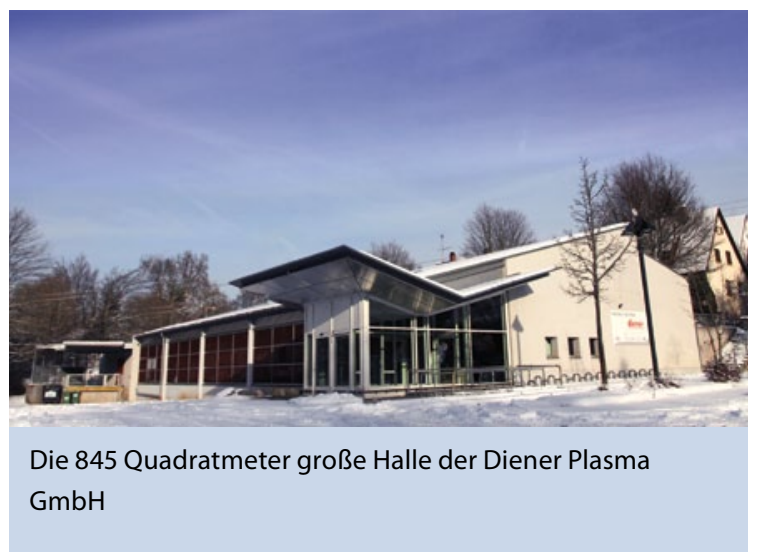

\section{Agtos plant weitere Investition in 2013}

D as stetige Firmenwachstum während der letzen Jahre lässt die Unternehmensleitung von Agtos optimistisch in die Zukunft blicken. Nach elf Jahren am Markt verzeichnet das Unternehmen in Emsdetten mit 70 Mitarbeitern den höchsten Personalbestand. Hinzu kommt der Standort Konin in Polen mit fast 80 Mitarbeitern. Nachdem im Jahr 2012 der Stammsitz in Emsdetten um- und ausgebaut und gleichzeitig die bereits im Jahr 2011 angestoßene Einführung der Konstruktion in 3D vorangetrieben wurde, besteht in 2013 weiterer Investitionsbedarf. So wird die etwa 4000 Quadratmeter große Produktionsfläche im Werk Konin nahezu verdoppelt. Ziel ist es, die Fertigungsabläufe zu optimieren und weitere Maschinen für Vorführzwecke aufzustellen. Zudem sollen neue Büro- und Konferenzräume entstehen. 